\title{
Mitigating SSR using DFIG-based Wind Generation
}

\author{
Lingling Fan, Senior Member, IEEE, Zhixin Miao, Senior Member, IEEE
}

\begin{abstract}
Subsynchronous resonance (SSR) phenomenon in wind farms connected with series compensated transmission network has been researched in recent literature. Mitigating SSR using FACTS devices such as TCSC, SVC and STATCOM has also been explored in the literature. The ability of the power converters in doubly-fed induction generator (DFIG) wind farms in mitigating SSR has rarely been investigated. In this paper, the DFIG converters will be explored for SSR mitigation. The investigation in this paper includes the design of auxiliary SSR damping controller and selection of control signals. Residuebased analysis, root locus diagrams, and time-domain simulation in Matlab/Simulink will be carried out. The major contributions of the paper are: 1) investigation of the potential of wind farm converters for SSR mitigation and 2) identification of an effective control signal for SSR damping controller to simultaneously enhance both sub- and super- synchronous resonance modes.
\end{abstract}

Index Terms-Doubly Fed Induction Generator, SSR mitigation

\section{INTRODUCTION}

Subsynchronous resonance (SSR) phenomenon in wind farms connected with series compensated transmission network has been researched in recent literature [1]-[3]. The mitigation of SSR using FACTS devices in series compensated transmission line connected with wind power has been presented in the literature. In [1], Varma et al explored TCSC and SVC's capability in SSR mitigation while in [3], STATCOM's capability in SSR mitigation is explored. The state-of-the-art wind energy systems use DFIGs with back-to-back power electronic converters. The capability of such converters in maximum power point tracking and voltage/reactive power control [4], compensation for unbalanced grid conditions [5] and oscillation stability [6], [7] has been explored in the literature. However the control ability of these converters in mitigating SSR has not yet been investigated.

A grid side converter (GSC) of a DFIG has a similar topology of a STATCOM yet exchanges both active and reactive power in fast speed. Hence, the objective of this paper is to explore the control capability of DFIG-based wind farms in mitigating SSR through an auxiliary damping controller at the GSC.

The unique feature of SSR phenomena in wind farms interfaced with series compensated network is that induction generator effect (IGE) due to the network resonant oscillatory mode is the major cause of SSR. This feature has been identified by the authors in [8]. The low shaft stiffness of wind turbine drive train leads to low frequency torsional modes [9], which rarely interact with the network resonant modes in the electric system. The frequency of torsional modes in wind turbines can be as low as 1-3 Hz. In order to have torsional

L. Fan and Z. Miao are with Dept. of Electrical Engineering, University of South Florida, Tampa FL 33620. Emails: fll@ieee.org. Phone: (813)974-2031. interaction, the network mode should have a frequency of 57$59 \mathrm{~Hz}$. This requires a very high level of series compensation which rarely happens.

The rotor speed has been used in SSR mitigation control [1], [3]. A preliminary study exploring the capability of the grid-side converters (GSC) of a DFIG in mitigating SSR is presented in [10]. The rotor speed of the wind farm is used as the input signal to the auxiliary SSR damping controller added to the GSC's reactive power/voltage control loop. The control scheme is demonstrated to enhance the SSR damping.

A question naturally arises: Is there a better signal for such SSR damping controller? Since the network resonant mode is the major cause of SSR, measurements closely related to such mode should be chosen as control signals. Hence both the line current and the voltage across the series compensation are chosen and their effectiveness in control design will be discussed in the paper.

Therefore, the objective of the paper is two-fold:

- to investigate the potential of SSR mitigation in DFIG converters

- to identify a control signal for SSR mitigation and for overall system stabilization enhancement.

The paper is organized as follows. Section II presents the study system, the DFIG converter controls and the auxiliary damping control for SSR mitigation. Section III presents residue-based analysis and root local diagram based verification to choose a control input signal. Section IV presents the simulation results to demonstrate the effectiveness of the SSR damping controllers. Section V concludes the paper.

\section{Study System And System Model}

The study system based on IEEE first benchmark model for SSR studies [11] is shown in Fig. 1 where a DFIG-based wind farm (100 MVA from the aggregation of $2 \mathrm{MW}$ units) is connected to a $161 \mathrm{kV}$ series-compensated line. The collective behavior of a group of wind turbines is represented by an equivalent lumped machine. This assumption is supported by several recent studies [12]-[15] that suggest that wind farm aggregation provides a reasonable approximation for system interconnection studies. This approach has also been practiced in system studies [16], [17] which points out that "simulations of bulk system dynamics using a single machine equivalent is adequate for most planning studies".

Two recent studies [1], [3] on SSR in wind farms have both used the IEEE first bench mark model or its derivation and an aggregated self-excited induction generator model to represent the wind farm. In [1], the power rating of the wind farm is $746 \mathrm{MW}$ and the transmission voltage level is $500 \mathrm{kV}$. In [3], the power rating of the wind farm is scaled down to $100 \mathrm{MW}$ and the voltage level of the transmission network is 
reduced to $132 \mathrm{kV}$. In this paper, an aggregated DFIG model is used and the voltage level of the transmission network is chosen to be $161 \mathrm{kV}$. The machine and the network parameters are listed in Appendix. The length of the transmission line is approximately 154 miles for which it is reasonable to install series compensation.

When individual wind turbines are aggregated, the aggregated inertia is scaled up. However the base power is also scaled up, therefore, the per unit value of the inertia $H$ does not change. The same also happens to other machine parameters such as impedances. Therefore, the parameters of a $2 \mathrm{MW}$ DFIG in per unit values can continue to be used for the equivalent wind generator.

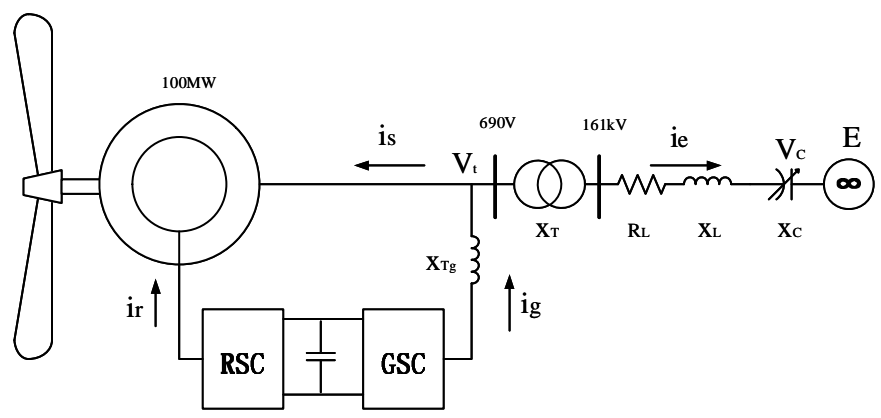

Fig. 1. The study system. The rated power of the wind farm is 100 MVA The nominal voltage of the wind farm terminal bus is $690 \mathrm{~V}$ and the nominal voltage of the network is $161 \mathrm{kV}$.

The differential equations based model of the study system for SSR study has been presented in [8]. Detailed modal analysis of system modes and impacting parameters have been studied in the authors' previous research [18]. In this paper, detailed discussion on differential equations and impacting parameters are omitted. The focus will be using residue method to select SSR mitigation input signal. As a summary, the complete dynamic system model includes the series compensated network model, the wind turbine aerodynamic model, the torsional dynamics model, the induction generator model, the dc-link model and the DFIG's converter controls. The auxiliary SSR damping control will be designed and added in for SSR mitigation study.

\section{A. DFIG Converter Controls}

Both rotor-side converter (RSC) and grid-side converter (GSC) controls are modeled in this study. Cascaded control loops similar to the ones in [19] are adopted in this paper. The control loops are shown in Figs. 2 and 3.

In the RSC control loops, the reference torque is obtained through the lookup table. When wind speed is greater than the rated speed, it is a constant value and is the optimal torque corresponding to the measured rotating speed. Through this lookup table, the wind turbine is able to extract the maximum wind power. The $q$-axis loop is to regulate the active power and the $d$-axis loop is to regulate the reactive power.

In the GSC control loops, the $q$-axis loop is to regulate the dc-link voltage and the $d$-axis loop is to regulate the terminal voltage as shown in Fig. 3.

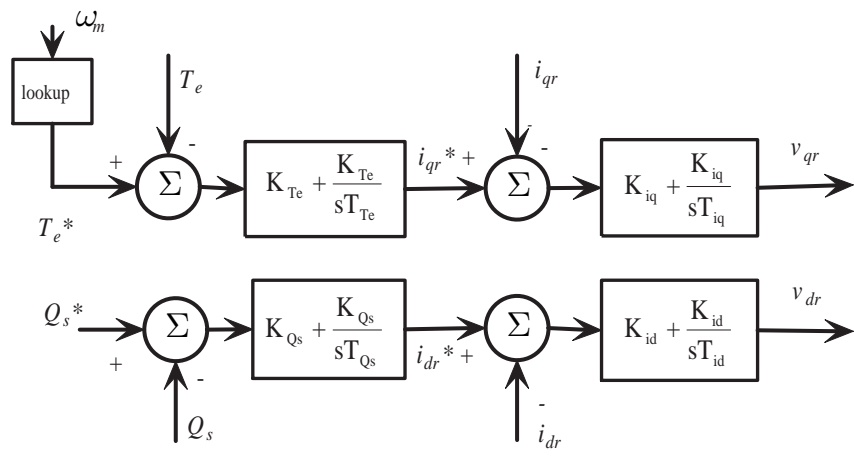

Fig. 2. RSC control loops.

\section{B. Auxiliary SSR Damping Control}

It has been identified in [2] and [8] that the RSC control loop gains negatively impact the SSR network mode and these gains have to be limited. It is therefore not suitable to explore SSR mitigation through RSCs. Instead, the focus is on GSC.

Supplementary control for SSR damping is proposed in STATCOM control [20]. The GSC is similar to a STATCOM in terms of the topology. The difference between STATCOM and GSC SSR mitigation is the consequent impact. For example, a GSC is connected to a RSC through an DC-link. Hence, SSR mitigation in GSC may cause impact on both GSC and RSC outputs. Similar as the SSR mitigation technique in STATCOM, the supplementary control is added in the GSC reactive power/voltage control loop for the $d$-axis to modulate the terminal voltage demand as shown in Fig. 3. This is Option 1.

Another option of modulation (Option 2) is through the DC-link voltage reference modulation. The dotted box and line show the SSR damping controller and the injection point. Modulation of the dc-link voltage reference is expected to cause more oscillations on the real power exchange through the dc-link and the electromagnetic torque.

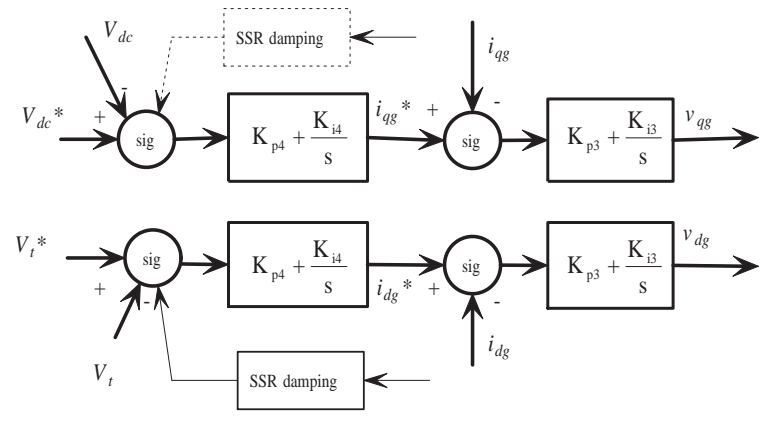

Fig. 3. Supplementary control schemes in the GSC control loop for SSR mitigation through either the terminal voltage modulation or dc-link voltage modulation.

\section{COMPARISON OF CONTROL InPUT Signals}

The unique feature of SSR phenomena in wind farms interfaced series compensated network is that induction generator effect due to the network resonant oscillatory mode is the 
major cause of SSR. This feature has been identified in a recent paper [8]. Torsional interactions in wind farms are rare because the torsional modes have a low frequency due to the low shaft stiffness of wind turbine drive trains [9].

The rotor speed $\omega_{r}$ is used in SSR mitigation control [1], [3]. In this paper, alternative or better control signals are identified. Since it is the network mode that is of the utmost concern, measurements closely related to such mode should be chosen as control signals. Both the line current magnitude and the voltage across the series compensation are chosen. Their effectiveness in control will be discussed in the following subsections.

\section{A. System Modes}

For the study system, the following system modes are listed and their characteristics are identified using mode shapes or participation factors. The shaft mode with a very low frequency $(<1 \mathrm{~Hz})$ is not listed in the tables.

TABLE I

SYSTEM MOdES AT VARIOUS WIND SPEEDS WITH A COMPENSATION LEVEL $75 \%$.

\begin{tabular}{||c|c|c|c||}
\hline \hline Mode & Mode 1 & Mode 2 & Mode 3 \\
\hline $7 \mathrm{~m} / \mathrm{s}$ & $-7.9 \pm j 628.7$ & $6.0 \pm j 125.5$ & $-11.5 \pm j 94.0$ \\
\hline $8 \mathrm{~m} / \mathrm{s}$ & $-7.5 \pm j 628.8$ & $0.9 \pm j 123.0$ & $-6.7 \pm j 58.1$ \\
\hline $9 \mathrm{~m} / \mathrm{s}$ & $-7.1 \pm j 629.0$ & $-1.1 \pm j 122.0$ & $-4.0 \pm j 22.1$ \\
\hline $10 \mathrm{~m} / \mathrm{s}$ & $-6.8 \pm j 629.0$ & $-2.2 \pm j 121.3$ & $-4.9 \pm j 21.5$ \\
\hline \hline
\end{tabular}

TABLE II

SYSTEM MOdES AT VARIOUS COMPENSATION LEVELS AT 7M/S WIND SPEED.

\begin{tabular}{||c|c|c|c||}
\hline \hline & Mode 1 & Mode 2 & Mode 3 \\
\hline $25 \%$ & $-5.3 \pm j 522.6$ & $-1.9 \pm j 230.7$ & $-4.1 \pm j 95.1$ \\
\hline $50 \%$ & $-6.6 \pm j 580.1$ & $-1.3 \pm j 172.4$ & $-5.9 \pm j 95.2$ \\
\hline $75 \%$ & $-7.9 \pm j 628.7$ & $6.0 \pm j 125.5$ & $-11.5 \pm j 94.0$ \\
\hline $90 \%$ & $-8.6 \pm j 652.7$ & $10.5 \pm j 109.3$ & $-15.9 \pm j 86.5$ \\
\hline \hline
\end{tabular}

A pair of complex eigenvalues $(\lambda=\sigma \pm j \omega)$ can be said to be a system mode with an oscillation frequency $f=\frac{\omega}{2 \pi}$. Damping ratio is defined as $D=\frac{-\sigma}{\sqrt{\sigma^{2}+\omega^{2}}}$. A positive real part of an eigenvalue indicates an unstable system with a negative damping.

From Table I and Table II, it is found that Mode 1 is a supersynchronous mode and Mode 2 is the network mode. Both modes are related to the compensation level. Mode 3 is identified through participation factor as a mode related to both rotor circuit dynamics and rotor speed dynamics.

The network resonance mode with a frequency of $f_{n}$ in stators will have a corresponding component induced in rotor circuits with a frequency of $\left( \pm f_{n}-f_{m}\right)$. Interactions of the stator current and the rotor current lead to the electromagnetic torque. Hence in the electromagnetic torque, besides the dc component, there will be two components, one with a frequency of $\left(60-f_{n}\right)$ (complementary of the SSR network mode) and the other with a frequency of $\left(60+f_{n}\right)$ for the supersynchronous mode. In this study, the models are built in a synchronous reference frame. Hence the network mode reflected in a stationary circuit with a frequency of $f_{n}$ has a frequency of $\left(60-f_{n}\right)$ when the stationary circuits are observed from the synchronous rotating reference frame. The supersynchronous mode is reflected in the electromagnetic torque which is not a circuit variable. Hence in the synchronous rotating reference frame, this mode will be observed to have a frequency of $\left(60+f_{n}\right)$.

The relation of the network mode (Mode 2) with wind speed and the compensation level has been analyzed in [8]: 1) the higher the compensation level, the less the damping of the network mode; and 2) the lower the wind speed, the less the damping of the network mode. This relation has been demonstrated in the eigenvalue analysis in Table I and II.

Mode 3 has a relatively large damping and hence Mode 1 and Mode 2 are the dominant system modes.

From Table I and II, at $7 \mathrm{~m} / \mathrm{s}$ and $75 \%$ compensation level, the network resonance mode has a frequency of $20 \mathrm{~Hz}$ in the synchronous reference frame based analysis, which indicates a $40 \mathrm{~Hz}$ resonance mode in the line currents in the physical system. The electromagnetic torque will have both a $20 \mathrm{~Hz}$ mode and a $100 \mathrm{~Hz}$ mode.

\section{B. Residues}

For different control signals, residues corresponding to the dominant system modes will be computed. The state-space model and the transfer function of a single-input single-output plant can be expressed as:

$$
\begin{aligned}
\dot{X} & =A X+B u \\
Y & =C X \\
\frac{Y(s)}{U(s)} & =G(s)=\Sigma_{i=1, \ldots, n} \frac{R_{i}}{s-\lambda_{i}} \\
R_{i} & =C V_{i} W_{i} B
\end{aligned}
$$

where $X$ is the vector of state variables, $A$ is the system matrix, $B$ is the input matrix, $C$ is the output matrix, $Y(s)$ is the plant output, $U(s)$ is the plant input, $\lambda_{i}$ is the $i$-th system root, $R_{i}$ is the residue corresponding to $\lambda_{i}, V_{i}$ is the i-th column of $V$ matrix and $W_{i}$ is the i-th row of $W$ matrix.

For a complex root $\lambda_{i}$, the residue $R_{i}$ is a complex number which can be denoted by a vector with direction. In a root locus diagram, $-R_{i}$ represents the direction and speed of the closed-loop eigenvalue $\lambda_{c i}$ leaving the pole $\lambda_{i}$. This concept has been approved in the first author's previous paper [21]. Hence residues are effective in selecting control signals and designing controllers.

A simple explanation of the residue is also presented in this paper. Assume that all the dynamics due to the other eigenvalues can be ignored and the open loop system dynamics can be expressed by only one eigenvalue $\lambda_{i}$. Then the plant transfer function becomes: $G(s)=\frac{R_{i}}{s-\lambda_{i}}$. The closed-loop system with a gain controller will have a transfer function with the following denominator: $1+K G(s)$ where $K$ is the gain of the feedback control. The root of the closed-loop system is determined by $1+K G(s)=0$, i.e., $\lambda_{c i}=\lambda_{i}-K R_{i}=0$. Hence the shift in the eigenvalue $\Delta \lambda_{i}$ can be expressed as

$$
\Delta \lambda_{i}=-K R_{i}
$$


Therefore $-R_{i}$ determines the direction of motion and speed of the closed-loop system root. The larger the magnitude of $R_{i}$, the more effective will be such feedback control.

The nonlinear system is first built in Matlab/Simulink. Linearization at equilibrium points (or operating conditions) can be conducted by an embedded Matlab function "linmod". The derived linear system is expressed in terms of $\dot{X}=A X+B U$ and $Y=C X$. For this study system, $U$ is the input and corresponds to the voltage injecting point at the GSC control loop in Fig. 4. $Y$ is the output of the system without SSR damping control or the input of SSR damping control. Y can be the rotor speed, line current or the voltage across the capacitor. Eigenvalues and eigenvectors can be computed using Matlab functions. From there, residues corresponding to eigenvalues can be computed based on (4). Since the linear system is derived based on one operating condition, with operating condition changes (wind speed or compensation level), residue changes as well.

Fig. 4 presents visual display of the residues at different operation conditions for the SSR mode (in blue) and the super synchronous mode (in magenta) when the rotating speed $\omega_{r}$ is the control signal. Figs. 5 and 6 present the visual display of the residues when the voltage $V_{c}$ or the line current $I_{\text {line }}$ is the control signal. A comparison of the residues of the three

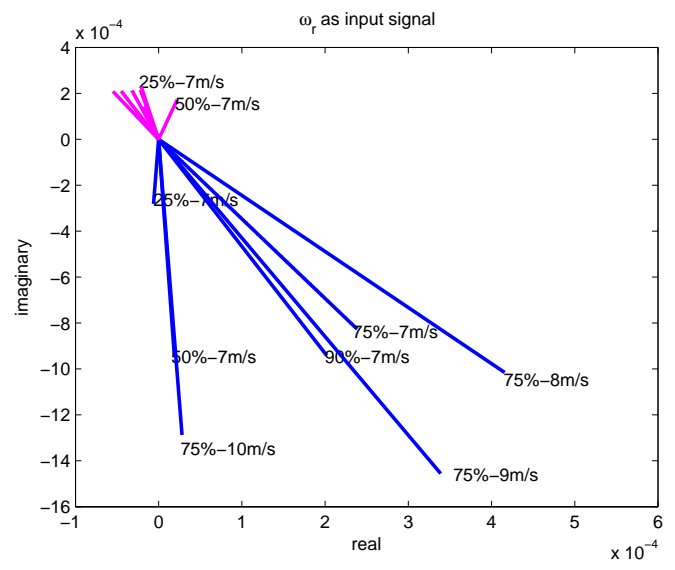

Fig. 4. Residues of the SSR mode (in blue) and the super synchronous mode (in magenta) with $\omega_{r}$ as the input signal.

signals leads to the following findings:

1) The residue magnitude of the SSR mode when the rotor speed $\omega_{r}$ is the control signal is very small. Hence the feedback control needs a large gain.

2) Residues of the SSR mode and the supersynchronous mode are of opposite polarity when the rotor speed $\omega_{r}$ or the line current $I_{\text {line }}$ is chosen as the control signal. This will increase the difficulty of controller design. A simple proportional controller will enhance the damping of the SSR mode but will decrease the damping of the supersynchronous mode.

3) Residues of the SSR mode and the supersynchronous mode are of same polarity when the voltage across the series compensator $V_{c}$ is chosen as the control signal. The design of the feedback control design using $V_{c}$ is fairly simple. A proportional feedback control is

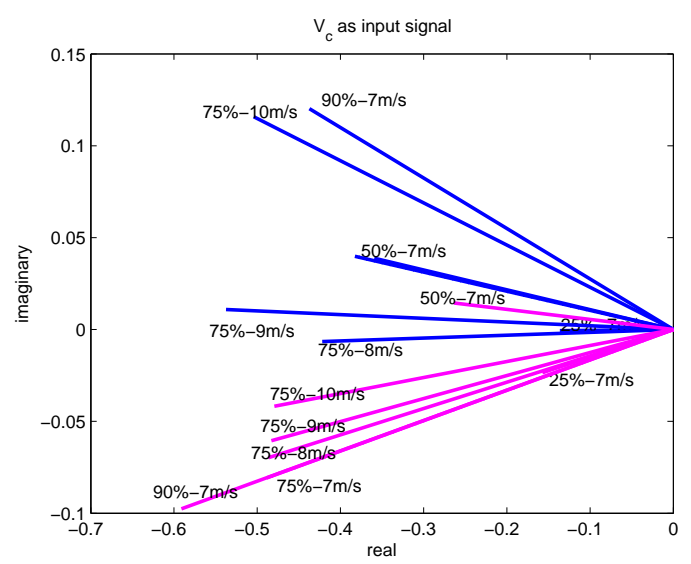

Fig. 5. Residues of the SSR mode (in blue) and the super synchronous mode (in magenta) with $V_{c}$ as the input signal.

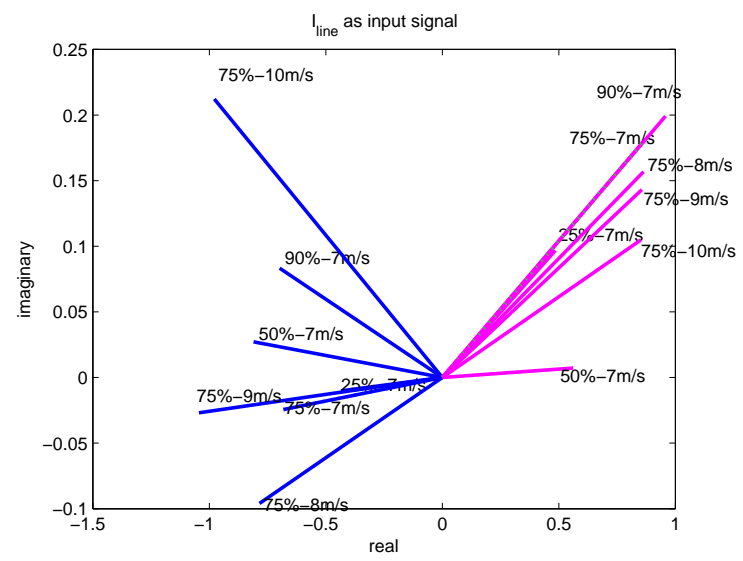

Fig. 6. Residues of the SSR mode (in blue) and the super synchronous mode (in magenta) with $I_{\text {line }}$ as the input signal.

sufficient to force both the SSR mode and the supersynchronous mode to move left thereby making the system stable.

The residues of the three signals for dc-link voltage modulation are also computed and plotted. To save the page, the results are not presented. Observations lead to the same conclusion that $V_{c}$ is the best signal for the SSR mitigation scheme.

\section{Root Locus Diagrams}

The above three findings can be verified through root locus diagrams. Figs. 7 and 8 are the root locus diagram when the rotor speed is used as the control signal for the two modulation scheme. For Option 1, with an increasing gain, the SSR mode and the supersynchronous mode will move in opposite directions. To have a 5\% damping ratio for the SSR mode, the gain should be selected to be 27000 . The supersynchronous mode will move towards right but will not cross the imaginary axis. The entire system is thus stable. For Option 2, it is found that a right half plane zero is introduced which makes the rotor speed an infeasible control signal.

Figs. 9 and 10 are the root locus diagrams when the voltage across the series capacitor $V_{c}$ is used as the control signal. 


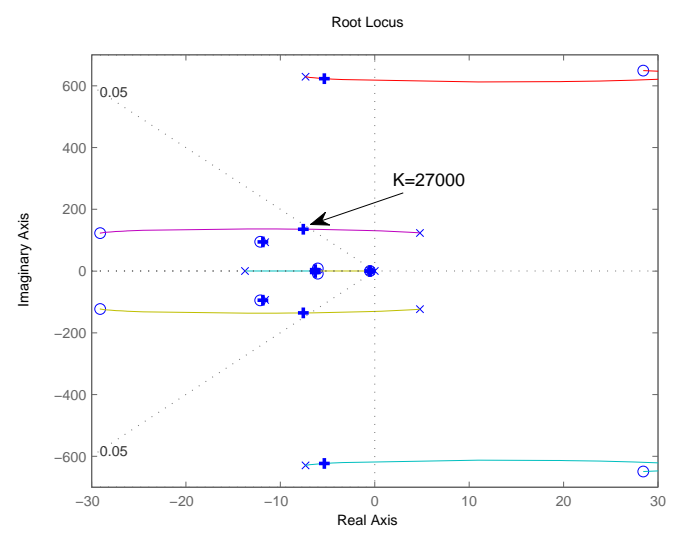

Fig. 7. Root locus diagram when the control signal is the rotor speed and $V_{t}^{*}$ is to be modulated. The "+" signs denote the locations of roots corresponding to the gain.

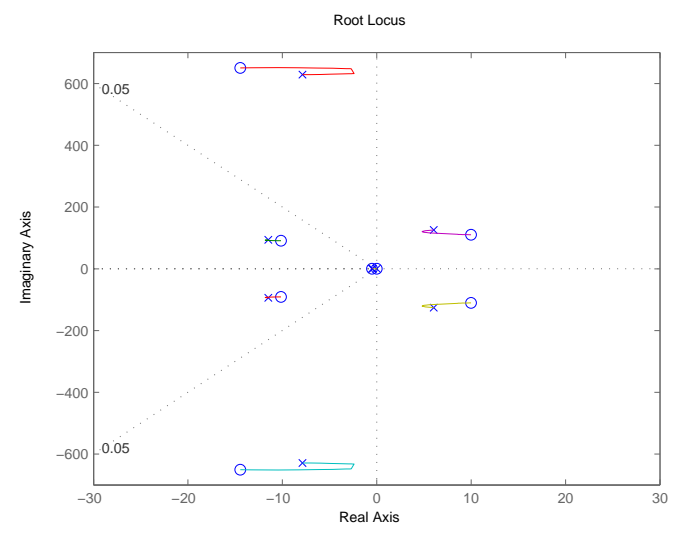

Fig. 8. Root locus diagram when the control signal is the rotor speed and $V_{d c}^{*}$ is to be modulated. The "+" signs denote the locations of roots corresponding to the gain.

In both modulation options, with an increasing gain, the SSR mode and the supersynchronous mode will both move towards the left plane. To have a 5\% damping ratio for the SSR mode, the gain should be selected to be 26.0726 for Option 1 and 46 for Option 2.

Figs. 11 and 12 are the root locus diagrams when the current through the line or the series capacitor is used as the control signal. With an increasing gain, the SSR mode and the supersynchronous mode will move in opposite directions. To have a 5\% damping ratio for the SSR mode, the gain should be selected to be 14 for Option 1 and 32 for Option 2 . The corresponding supersynchronous mode will move to the right plane and have a negative damping. The entire system is unstable.

Important finding from the root locus diagrams include:

- A right half plane zero will be introduced when the rotor speed is used as the control signal for dc-link voltage modulation. This indicates that rotor speed is not a universally good signal for SSR damping.

- The root locus diagrams corroborate the residue-based analysis and the capacitor voltage is the best control

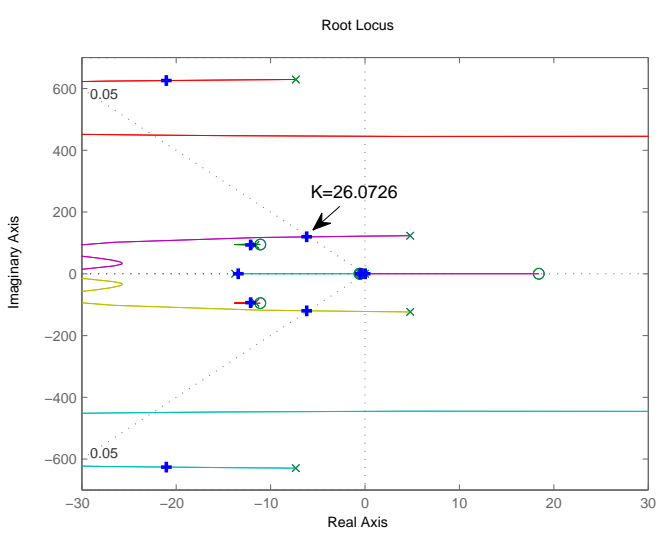

Fig. 9. Root locus diagram when the control signal is the capacitor voltage and $V_{t}^{*}$ is to be modulated. The "+" signs denote the locations of roots corresponding to the gain.

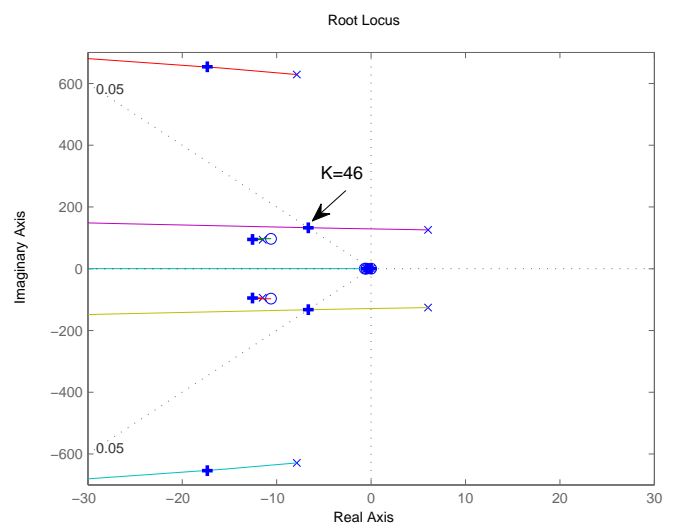

Fig. 10. Root locus diagram when the control signal is the capacitor voltage and $V_{d c}^{*}$ is to be modulated. The "+" signs denote the locations of roots corresponding to the gain.

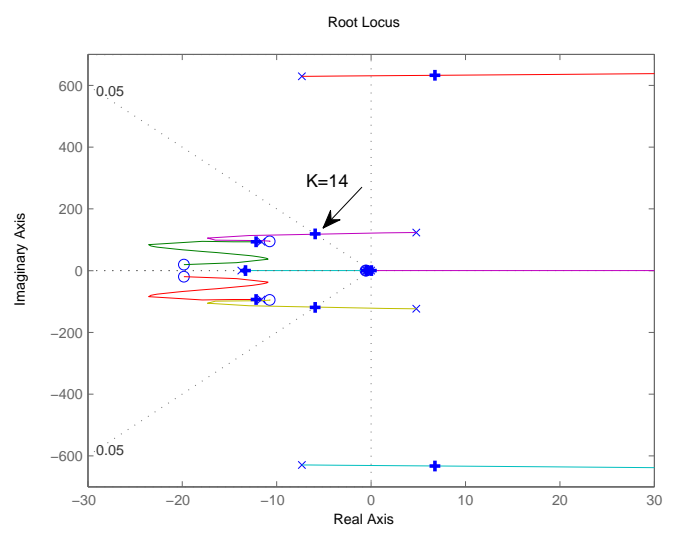

Fig. 11. Root locus diagram when the control signal is the line current and $V_{t}^{*}$ is to be modulated. The "+" signs denote the locations of roots corresponding to the gain. 


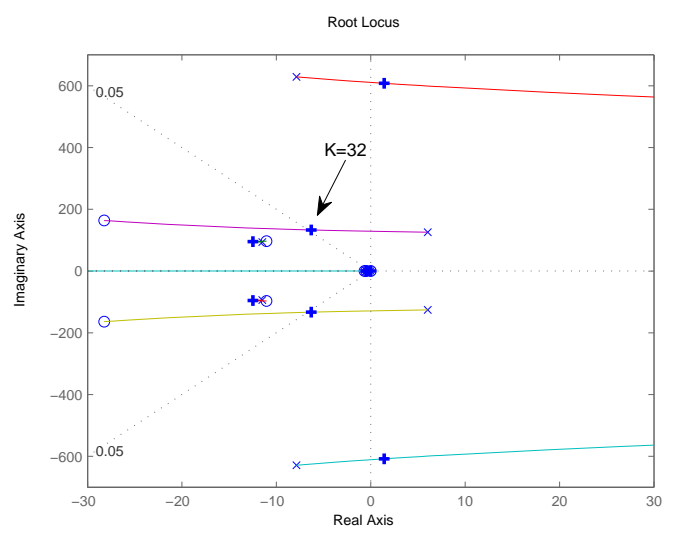

Fig. 12. Root locus diagram when the control signal is the line current and $V_{d c}^{*}$ is to be modulated. The "+" signs denote the locations of roots corresponding to the gain.

signal.

\section{Discussion of two signals $I_{\text {line }}$ and $V_{c}$}

The current magnitude $I_{\text {line }}$ and the capacitor voltage magnitude $V_{c}$ show radically different control characteristics at the SSR and super synchronous frequencies. One may wonder what is the cause since the two phasors of the fundamental frequency have their magnitudes proportional to each other and a 90 degree phase shift at steady state.

To explain the relationship between the two phasors at dynamics, the concept of dynamic phasor [22] is used. We assume that the network is operating under $60 \mathrm{~Hz} \mathrm{AC}$. The instantaneous current and voltage have a relationship given by:

$$
C \frac{d v_{c, p}}{d t}=i_{\text {line }, p}, \text { where } p=a, b, c .
$$

Therefore, the relationship of the two dynamic phosors of the fundamental frequency $(60 \mathrm{~Hz})$ can be written as:

$$
C \frac{d V_{1, c}}{d t}=I_{1, l i n e}-j \omega_{s} C V_{1, c}
$$

where $V_{1, c}$ and $I_{1, l}$ are two complex phasors for fundamental frequency $\omega_{s}$.

The above equation will be separated based on real and imaginary components:

$$
\left\{\begin{array}{l}
\mathfrak{R} V=\frac{s \Re I+\omega_{s} \mathfrak{I} I}{C\left(s^{2}+\omega_{s}^{2}\right)} \\
\mathfrak{I} V=\frac{s \mathfrak{I}-\omega_{s} \Re I}{C\left(s^{2}+\omega_{s}^{2}\right)}
\end{array}\right.
$$

where $\mathfrak{R}$ and $\mathfrak{I}$ denote the real and imaginary parts of a variable. For simplicity, the subscripts of the two phasors are omitted.

In time domain, the magnitude of a phasor can be expressed as $|I|=\left(\mathfrak{R} I^{2}+\Im I^{2}\right)^{\frac{1}{2}}$. The linearized expression is hence given by:

$$
\left\{\begin{array}{l}
\Delta|I|=\frac{1}{|I|}(\mathfrak{R} I \Delta \mathfrak{R} I+\mathfrak{I} I \Delta \mathfrak{I} I) \\
\Delta|V|=\frac{1}{|V|}(\mathfrak{R} V \Delta \mathfrak{R} V+\mathfrak{I} V \Delta \mathfrak{I} V)
\end{array}\right.
$$

In s-domain, $\Delta|V|$ can be expressed in terms of $\Delta \Re I$ and $\Delta \mathfrak{I} I)$ due to (8). The s-domain expression is given by:

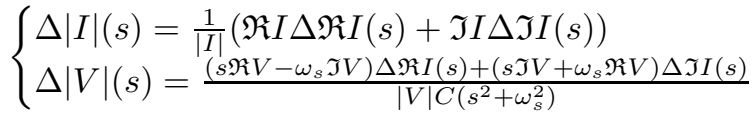

The above expression demonstrates the complicated relationship between $\Delta|V|(s)$ and $\Delta|I|(s)$. Assumptions are made to derive a simple expression between $\Delta|V|(s)$ and $\Delta|I|(s)$. Let $\mathfrak{R} V=\mathfrak{I} V$ at certain operation condition and let $\Delta \mathfrak{R} I(s)=\Delta \mathfrak{I} I(s)$. Equation (10) becomes

$$
\left\{\begin{array}{l}
\left.\Delta|I|(s)=\frac{1}{|I|}(\mathfrak{R} I+\Im I) \Delta \mathfrak{R} I(s)\right) \\
\Delta|V|(s)=\frac{(2 s \mathfrak{R} V \mathfrak{R} I(s)}{|V| C\left(s^{2}+\omega_{s}^{2}\right)}
\end{array} .\right.
$$

Finally a simplified relationship is derived:

$$
\Delta|V|(s)=K \frac{s}{s^{2}+\omega_{s}^{2}} \Delta|I|(s)=H(s)|I|(s)
$$

where $K$ is a constant depending on the operation conditions. $H(s) / K$ is plotted in a Bode plot in Fig. 13. It is found from

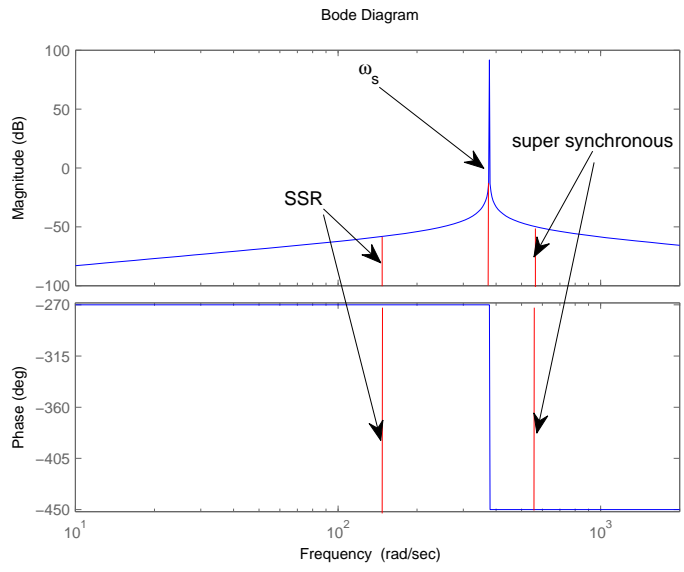

Fig. 13. Bode plots for the transfer function $H(s)$.

the bode plot that $H(s)$ at SSR frequency has a phase angle of -270 degree while at the super synchronous frequency the phase angle is -450 degree. There is a 180 degree difference. This can explain why $V_{c}$ and $I_{\text {line }}$ can have very different control characteristics at the SSR and super synchronous frequencies.

\section{Simulation Results}

Previous study in [8] shows that when wind speed is $7 \mathrm{~m} / \mathrm{s}$, the system can suffer SSR instability when the compensation level reaches $75 \%$ due to IGE. In the simulation study, initially, the compensation level is set at $50 \%$. At $t=1 \mathrm{~s}$, the compensation level changes to $75 \%$. The dynamic responses of the system with and without SSR damping controller are plotted. A pure proportional control will be used for the SSR damping controller.

Total four scenarios were simulated and they are:

- Case 1: no SSR controller is implemented. 
- Case 2: A damping controller is implemented with $I_{\text {line }}$ as the input signal and $\Delta V_{t}^{*}$ as the output signal. The gain of the controller is 10 .

- Case 3: A damping controller is implemented with $V_{c}$ as the input signal and $\Delta V_{t}^{*}$ as the output signal. The gain is chosen to be 30 .

- Case 4: A damping controller is implemented with $V_{c}$ as the input signal and $\Delta V_{d c}^{*}$ as the output signal. The gain is 46 .

\section{A. Case 1}

Fig. 14 shows a comparison of the dynamic responses of the electromagnetic torque $T_{e}$ and the line current $I_{\text {line }}$. The red denotes the system with the SSR damping controller (Case 3) while the blue line denotes the system without SSR damping controller. It is found that the system without damping control becomes unstable when the series compensation level increases to $75 \%$, while with the damping controller, the system remains stable.
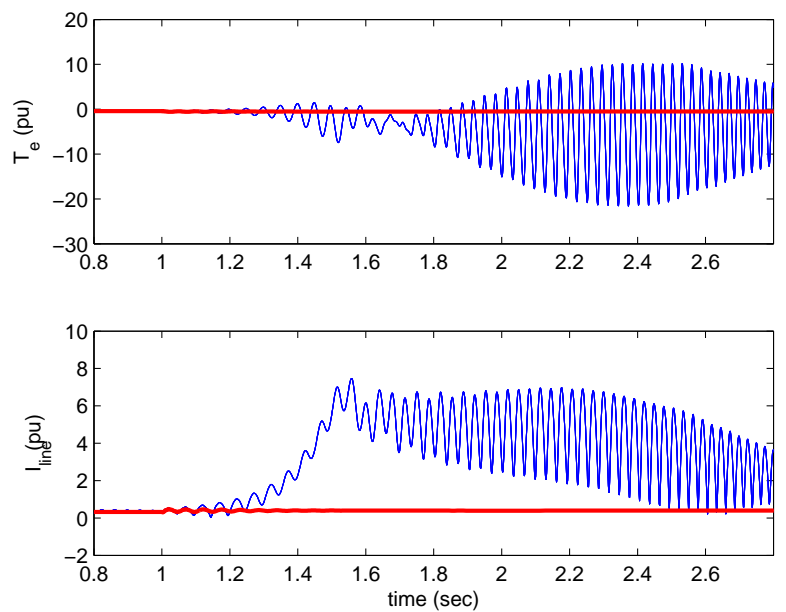

Fig. 14. Dynamic responses of $T_{e}$ and the line current $I_{\text {line }}$. The thick line denotes the dynamic response with SSR damping controller while the thin line denotes the dynamic response without SSR damping controller. $V_{c}$ is used as the control signal.

\section{B. Case 2}

In Case 2, a damping controller is implemented with $I_{\text {line }}$ as the input signal and $\Delta V_{t}^{*}$ as the output signal. The gain of the controller is 10. The simulation results are shown in Figs. 15-17. The system is unstable in this case.

It is observed from Figs. 15-17 that there exist harmonics in the waveforms. The network resonance mode has a frequency of $40 \mathrm{~Hz}$, which induces both $20 \mathrm{~Hz}$ and $100 \mathrm{~Hz}$ oscillations in $T_{e}$. In the synchronous reference frame based simulation results, the SSR mode has a frequency of $20 \mathrm{~Hz}$ while the supersynchronous mode has a frequency of about $100 \mathrm{~Hz}$. The two superimposed on each other result a waveform of $20 \mathrm{~Hz}$ with 5th harmonic. The simulation results confirms the analysis in Section III that when the line current is used as the input signal, the damping of the SSR mode increases while the damping of the supersynchronous mode decreases.
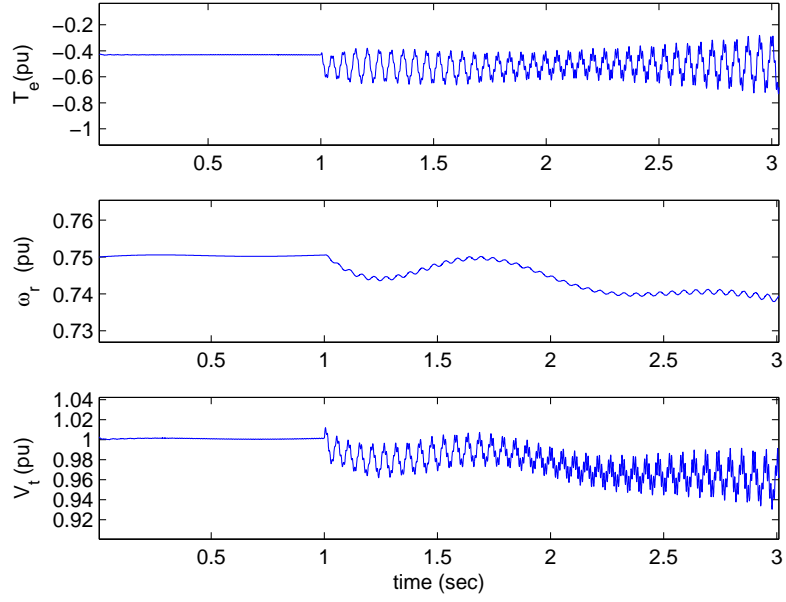

Fig. 15. Dynamic responses of $T_{e}$ and $\omega_{r}$. a) Electromagnetic torque $T_{e}$, b) rotor speed $\omega_{r}$, c) terminal voltage $V_{t} . I_{\text {line }}$ is used as the control signal.
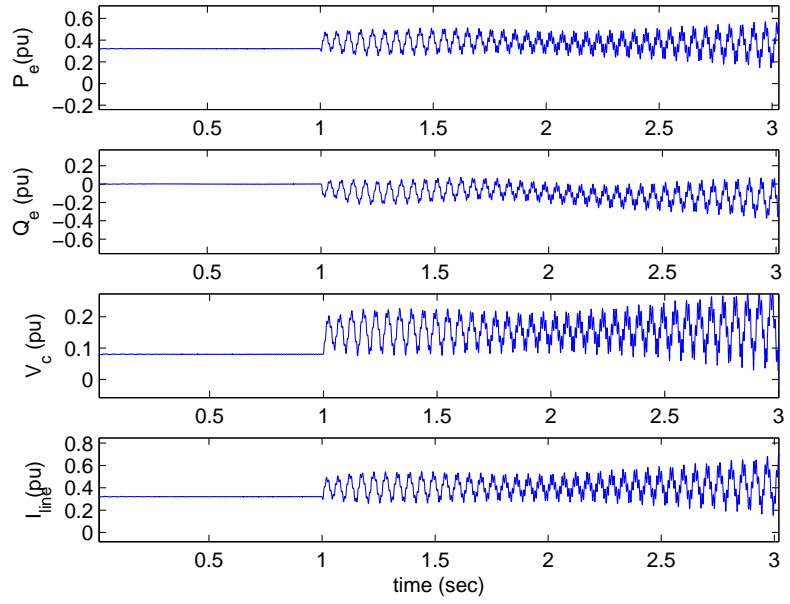

Fig. 16. Dynamic responses. a) DFIG output power $P_{e}$, b) DFIG exporting reactive power $Q_{e}$, c) RMS voltage across the capacitor $V_{c}$, d) RMS line current $I_{\text {line. }} I_{\text {line }}$ is used as the control signal.
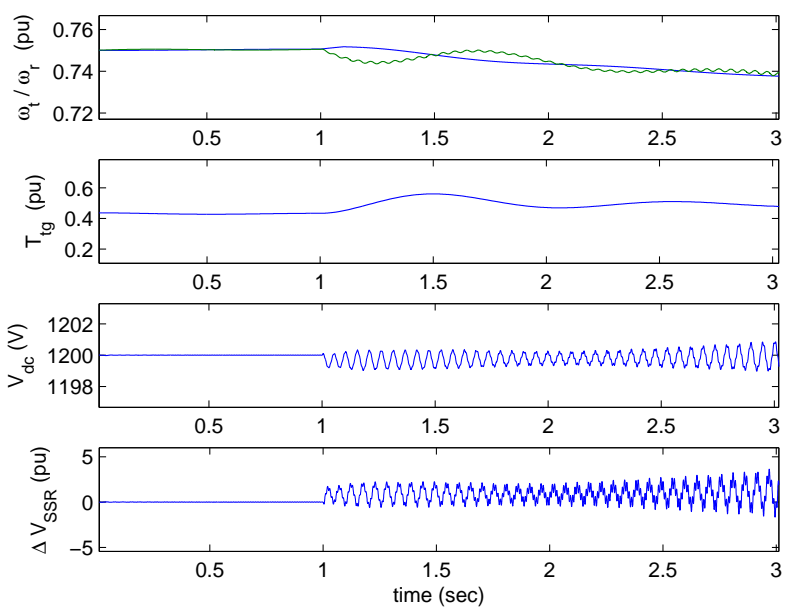

Fig. 17. Dynamic responses. a) $\omega_{t} / \omega_{r}$, b) $T_{t g}$, c) $V_{d c}$, d) the output of the SSR damping controller $\Delta V_{S S R}$. $I_{\text {line }}$ is used as the control signal. 


\section{Case 3 and Case 4}

In Case 3 and Case $4, V_{c}$ is used as the input SSR damping controller signal. Either the terminal voltage $V_{t}$ or the dc-link voltage $V_{d c}$ will be modulated. Figs. 18-20 show the dynamic responses of the system with such kind of damping controllers. The two modulation options are compared by plotting the dynamic responses together. The red lines denote the dynamic responses for Case 3 when $V_{t}$ is modulated. The thick blue lines denote the dynamic responses for Case 4 when $V_{d c}$ is modulated.

The dynamic responses of Electromagnetic torque $T_{e}$, rotor speed $\omega_{r}$, and the terminal voltage $V_{t}$ are shown in Fig. 18. It is clearly shown in $T_{e}$, there is a $20 \mathrm{~Hz}$ oscillation. This is the SSR oscillation caused by a $40 \mathrm{~Hz}$ network resonance mode. In turn, the rotor speed will show a $20 \mathrm{~Hz}$ ripple.

The dynamic responses of the DFIG's output power $P_{e}$ and reactive power $Q_{e}$, the RMS voltage across the series capacitor $V_{c}$ and the RMS current through the transmission line $I_{\text {line }}$ are shown in Fig. 19. The dynamic responses of the speed of the rotating masses in the wind turbine, the torque between the two masses $T_{t g}$, the dc-link voltage and the output of the SSR damping controller are shown in Fig. 20. The $20 \mathrm{~Hz}$ oscillation due to SSR is obvious in the dc-link voltage, line current, capacitor voltage, real and reactive power. It is observed that with either one of the damping options, SSR is effectively mitigated.
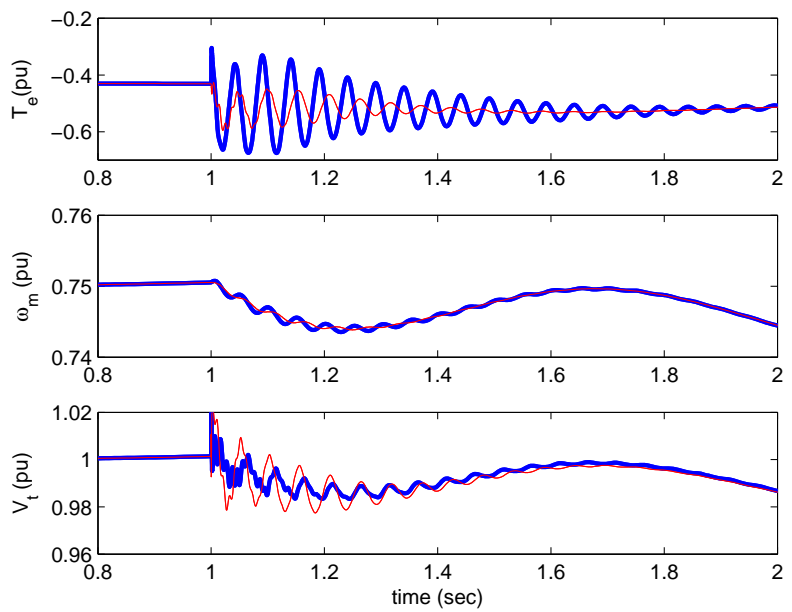

Fig. 18. Dynamic responses of $T_{e}$ and $\omega_{r}$. a) Electromagnetic torque $T_{e}$, b) rotor speed $\omega_{r}$, c) terminal voltage $V_{t} . V_{c}$ is used as the control signal.

It is found that the magnitude of the oscillations in the electromagnetic torque $T_{e}$, dc-link voltage $V_{d c}$ will be greater than when $V_{d c}$ is modulated.

The following observations can also be made from Figs. 18-20:

- Both the transmission line current and the voltage across the series capacitor reflect the SSR oscillation well.

- Though the electromagnetic torque reflects the SSR oscillation, the rotor speed reflect mainly the torsional mode.

- The terminal voltage shows SSR oscillation due to the damping controller.

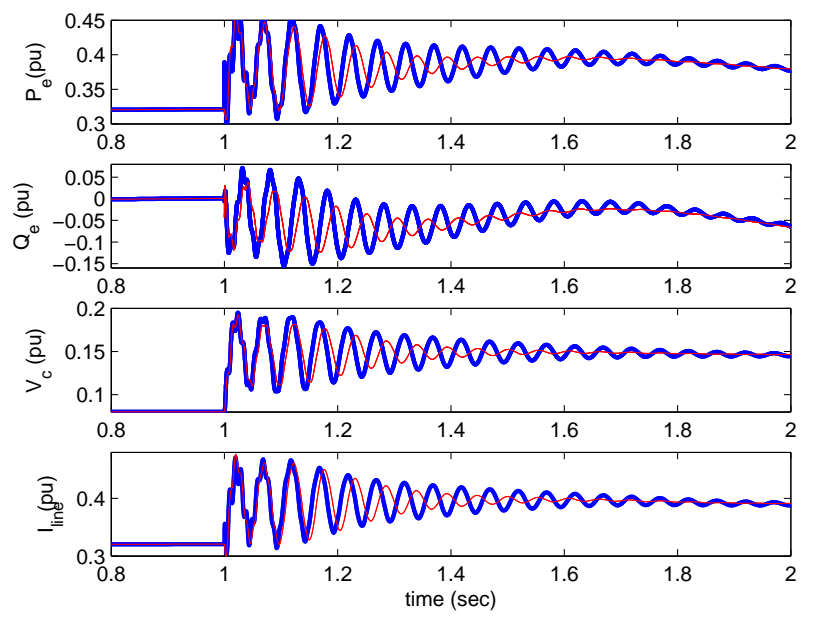

Fig. 19. Dynamic responses. a) DFIG output power $P_{e}$, b) DFIG exporting reactive power $Q_{e}$, c) RMS voltage across the capacitor $V_{c}$, d) RMS line current $I_{\text {line }} . V_{c}$ is used as the control signal.

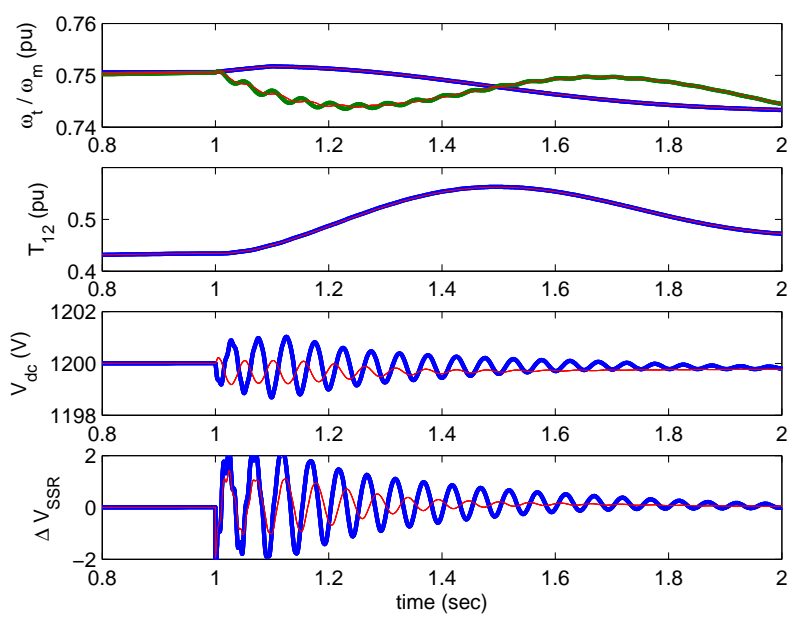

Fig. 20. Dynamic responses. a) $\omega_{t} / \omega_{r}$, b) $T_{t g}$, c) $V_{d c}$, d) the output of the SSR damping controller $\Delta V_{S S R}$. $V_{c}$ is used as the control signal.

Overall, the control signal $\left(V_{c}\right)$ can effectively damp SSR oscillations.

The performance of the auxiliary controller will be impacted by the converter's limitation on current and voltage. Since the purpose of the paper is to choose a control signal through small-signal based analysis. In the simulation studies since the wind speed is low, both the machine and the converters will have large reserves. Our future work will investigate different operating conditions and large signal disturbance scenarios to determine the effect of converter size on controller performance.

\section{Discussion of the Remote Signal Issue}

The analysis and verification carried out in this research demonstrates that the capacitor voltage is an effective control signal for SSR mitigation. The following question remains: the control is implemented in wind farms and the series compensation could be far from the location. Obtaining the remote signal 
from communication links could be very expensive. Can an estimation algorithm be used to estimate the capacitor voltage through the local current measurements?

Fortunately, the answer is Yes. The relationship between the instantaneous current through the line $i_{p}$ and the instantaneous voltage across the capacitor $v_{c, p}$ is given by:

$$
C \frac{d v_{c, p}}{d t}=i_{p}, \text { where } p=a, b, c .
$$

Therefore, the capacitor voltage can be estimated through the local current measurements. The following figure (Fig. 21) presents the estimation diagram of obtaining the estimated voltage magnitude from the abc instantaneous current measurements. Three integral units will be used to obtain another set of signals $i_{a}^{\prime}, i_{b}^{\prime}$ and $i_{c}^{\prime}$. These signals are proportional to the instantaneous capacitor voltage. Through abc to dq reference frame transformation, three-phase balanced variables can be transformed into two dc variables. The fundamental component phasor magnitude can then be computed from the two de variables.

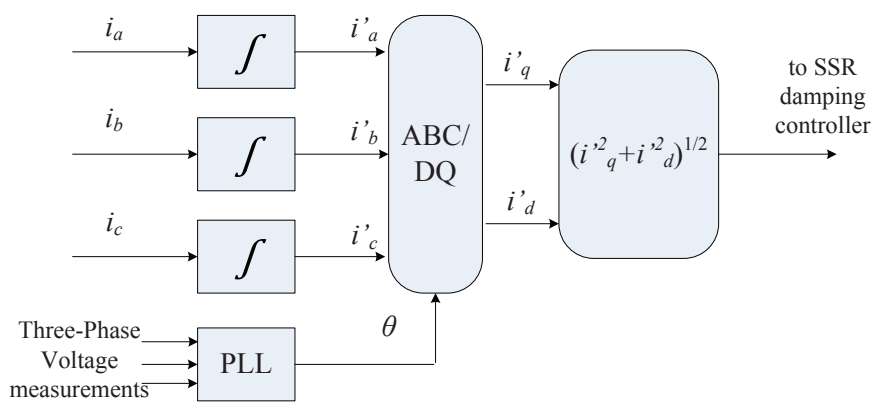

Fig. 21. Observer to estimate the capacitor voltage $V_{c}$ through local measurement of currents $i$.

\section{CONCLUSIONS}

This paper explores the control capability of DFIG-based wind farms for SSR mitigation. Auxiliary damping control schemes to modulate either the terminal voltage or the dclink voltage references of the grid side converter controls are proposed for SSR mitigation. Effective control signals are examined using residue-based analysis, root locus diagram verification and time-domain simulation validation. Important findings from the paper include: (i) Rotor speed has been used as the control signal for SSR mitigation using STATCOM in the literature. For this particular application, rotor speed as the control signal with the dc-link voltage reference being modulated is shown to introduce a right half plane zero. Hence rotor speed is not a feasible control signal. (ii) Capacitor voltage is demonstrated to be an effective signal to enhance damping for both SSR and supersynchronous modes. Though it is a remote signal, it can be estimated through local measurements.

\section{APPENDIX}

The parameters of the DFIG and study system are shown in Tables III-VI.
TABLE III

PARAMETERS OF A SINGLE 2 MW DFIG AND THE AGgREGATEd DFIG IN NETWORK SYSTEM

\begin{tabular}{|c|c|c|}
\hline Rated power & $2 \mathrm{MW}$ & $100 \mathrm{MW}$ \\
\hline Rated voltage & $690 \mathrm{~V}$ & $690 \mathrm{~V}$ \\
\hline$X_{l s}$ & $0.09231 \mathrm{pu}$ & $0.09231 \mathrm{pu}$ \\
\hline$X_{M}$ & $3.95279 \mathrm{pu}$ & $3.95279 \mathrm{pu}$ \\
\hline$X_{l r}$ & $0.09955 \mathrm{pu}$ & $0.09955 \mathrm{pu}$ \\
\hline$R_{s}$ & $0.00488 \mathrm{pu}$ & $0.00488 \mathrm{pu}$ \\
\hline$R_{r}^{\prime}$ & $0.00549 \mathrm{pu}$ & $0.00549 \mathrm{pu}$ \\
\hline$H$ & $3.5 \mathrm{~s}$ & $3.5 \mathrm{~s}$ \\
\hline$X_{t g}$ & $0.3 \mathrm{pu}(0.189 \mathrm{mH})$ & $0.3 \mathrm{pu}\left(\frac{0.189}{5} \mathrm{mH}\right)$ \\
\hline DC link capacitor C & $14000 \mu F$ & $50 \times 14000 \mu \mathrm{F}$ \\
\hline DC link rated voltage & $1200 \mathrm{~V}$ & $1200 \mathrm{~V}$ \\
\hline \hline
\end{tabular}

TABLE IV

PARAMETERS OF THE SHAFT SYSTEM

\begin{tabular}{|c|c|}
\hline$H_{1}$ & $0.9 \mathrm{~s}$ \\
\hline$H_{2}$ & $4.29 \mathrm{~s}$ \\
\hline$D_{1}$ & $0 \mathrm{pu}$ \\
\hline$D_{2}$ & $0 \mathrm{pu}$ \\
\hline$D_{12}$ & $1.5 \mathrm{pu}$ \\
\hline$K_{12}$ & $0.15 \mathrm{pu}$ \\
\hline
\end{tabular}

\section{REFERENCES}

[1] R. K. Varma, S. Auddy, and Y. Semsedini, "Mitigation of subsynchronous resonance in a series-compensated wind farm using FACTS controllers," IEEE Trans. Power Del., vol. 23, no. 3, pp. 1645-1654, Jul. 2008.

[2] A. Ostadi, A. Yazdani, and R. Varma, "Modeling and stability analysis of a DFIG-based wind-power generator interfaced with a seriescompensated line," IEEE Trans. Power Del., vol. 24, no. 3, pp. 15041514, Jul. 2009

[3] M. S. El-Moursi, B. Bak-Jensen, and M. H. Abdel-Rahman, "Novel STATCOM controller for mitigating SSR and damping power system oscillations in a series compensated wind park," IEEE Trans. Power Electron., vol. 25, no. 2, pp. 429-441, Feb. 2010.

[4] A. Tapia, G. Tapia, J. X. Ostolaza, and J. R. Saenz, "Modeling and control of a wind turbine driven doubly fed induction generator," IEEE Trans. Energy Convers., vol. 18, no. 2, pp. 194-204, Jun. 2003.

[5] L. Xu and Y. Wang, "Dynamic modeling and control of dfig-based wind turbines under unbalanced network conditions," IEEE Trans. Power Syst., vol. 22, no. 1, pp. 314-323, Feb. 2007.

[6] F. M. Hughes, O. Anaya-Lara, N. Jenkins, and G. Strbac, "A power system stabilizer for DFIG-based wind generation," IEEE Trans. Power Syst., vol. 21, pp. 763-772, May 2006.

TABLE V

PARAMETERS OF THE NETWORK SYSTEM

\begin{tabular}{|c|c|}
\hline Transformer ratio & $690 \mathrm{~V} / 161 \mathrm{kV}$ \\
\hline Transformer $X_{T}$ & $0.14 \mathrm{pu}$ \\
\hline Base MVA & $100 \mathrm{MVA}$ \\
\hline$R_{L}$ & $0.02 \mathrm{pu}(5.1842 \Omega)$ \\
\hline$X_{L}$ & $0.5 \mathrm{pu}(129.605 \Omega)$ \\
\hline$X_{C}$ at 50\% compensation level & $64.8 \Omega$ \\
\hline Series compensation $\mathrm{C}$ & $40 \mu \mathrm{F}$ \\
\hline Line length & $154 \mathrm{mile}$ \\
\hline
\end{tabular}

TABLE VI

PARAMETERS OF THE CONTROL LOOPS IN A DFIG

\begin{tabular}{|c|c||c|c|}
\hline$T_{T_{e}}$ & 0.025 & $T_{Q_{s}}$ & 0.05 \\
\hline$T_{i q}$ & 0.0025 & $T_{i d}$ & 0.005 \\
\hline$K_{T_{e}}$ & 0.1 & $K_{Q_{s}}$ & 0.1 \\
\hline$K_{i q}$ & 0.0 & $K_{i d}$ & 0.0 \\
\hline$K_{p 3}$ & 1 & $K_{i 3}$ & 100 \\
\hline$K_{p 4}$ & 0.1 & $K_{i 4}$ & 0.05 \\
\hline
\end{tabular}


[7] Z. Miao, L. Fan, D. Osborn, and S. Yuvarajan, "Control of DFIG-based wind generation to improve interarea oscillation damping," IEEE Trans. Energy Convers., vol. 24, no. 2, pp. 415-422, Jun. 2009.

[8] L. Fan, R. Kavasseri, Z. Miao, and C. Zhu, "Modeling of DFIG-based wind farms for SSR analysis," IEEE Trans. Power Del., vol. 25, no. 4, pp. 2073-2082, Oct. 2010.

[9] F. Mei and B. Pal, "Modal analysis of grid-connected doubly fed induction generators," IEEE Trans. Energy Convers., vol. 22, no. 3, pp. 728-736, Aug. 2007.

[10] C. Zhu, L. Fan, and M. Hu, "Control and analysis of DFIG-based wind turbines in a series compensated network for SSR damping," in IEEE Power \& Energy General Meeting, Minneapolis, MN, Jul. 2010.

[11] IEEE Committee Report, "First benchmark model for computer simulation of subsynchronous resonance," IEEE Trans. Power and Apparatus Systems, vol. 96, no. 5, pp. 1565-1672, Sep./Oct. 1977.

[12] L. M. Fernandez, F. Jurado, and J. R. Saenz, "Aggregated dynamic model for wind farms with doubly fed induction generator wind turbines," Renewable Energy, vol. 33, pp. 129-140, 2008.

[13] J. T. Bialasiewics and E. Muljadi. (2006, Nov.) The wind farm aggregation impact on power quality. National Renewable Energy Laboratory report. [Online]. Available: http://www.nrel.gov/wind/pdfs/39870.pdf

[14] E. Muljadi and B. Parsons, "Comparing single and multiple turbine representations in a wind farm simulation," in European Wind Energy Conference, Athens, Greece, 2006.

[15] M. Poller and S. Acchilles, "Aggregated wind park models for analyzing power system dynamics," in 4th International Workshop on Large-Scale Integration of Wind Power and Transmission Networks for Offshore Wind Farms, Billund, Denmark, 2003.

[16] N. W. Miller, W. W. Price, and J. J. Sanchez-Gasca, "Dynamic modeling of ge 1.5 and 3.6 wind turbine-generators," GE-Power Systems Energy Consulting, General Electric International, Inc., Schenectady, NY, Oct. 2003.

[17] R. Piwko, N. Miller, J. Sanchez-Gasca, X. Yuan, R. Dai, and J. Lyons, "Integrating large wind farms into weak power grids with long transmission lines," in IEEE/PES Transmission and Distribution Conference \& Exhibition: Asia and Pacific, Dalian, China, 2005.

[18] L. Fan, C. Zhu, Z. Miao, and M. Hu, "Modal analysis of a DFIG-based wind farm interfaced with a series compensated network," IEEE Trans. Energy Convers., vol. 26, no. 4, pp. 1010-1020, Dec. 2011.

[19] F. Mei and B. C. Pal, "Modelling of dobuly-fed induction generator for power system stability study," Proceedings of IEEE Power \& Energy General Meeting 2008, Jul. 2008.

[20] K. Padiyar and N. Prabhu, "Design and performance evalution of subsynchronous damping controller with STATCOM," IEEE Trans. Power Del., vol. 21, no. 3, pp. 1398-1405, Jul. 2006.

[21] L. Fan, A. Feliachi, and K. Schoder, "Selection and design of a TCSC control signal in damping power system inter-area oscillations for multiple operating conditions," Electric Power Systems Research, vol. 62, no. 2, pp. 127-137, Jun. 2002.

[22] D. Maksimovic, A. Stankovic, V. Thottuvelil, and G. Verghese, "Modeling and simulation of power electronic converters," Proceedings of IEEE, vol. 89, no. 6, pp. 898-912, Jun. 2001.

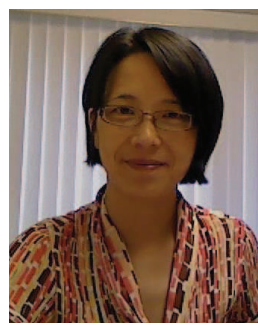

Lingling Fan (S'99-M'02-SM'08) received the B.S. and M.S. degrees in electrical engineering from Southeast University, Nanjing, China, in 1994 and 1997, respectively, and the Ph.D. degree in electrical engineering from West Virginia University, Morgantown, WV, in 2001.

She is currently an Assistant Professor in the Department of Electrical Engineering, University of South Florida (USF). Before joining USF, she was with North Dakota State University (2007-2009) and Midwest ISO (2001-2007). Her research interests include smart grid and power electronics.

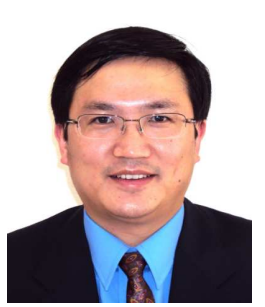

Zhixin Miao (S'00-M'03-SM'09) received the B.S. degree from Huazhong University of Science \& Technology, Wuhan, China, in 1992, the M.S. degree from the Graduate School of Nanjing Automation Research Institute in 1997, and the Ph.D. degree in electrical engineering from West Virginia University, Morgantown, in 2002.

$\mathrm{He}$ is currently an Assistant Professor in the Department of Electrical Engineering, University of South Florida (USF), Tampa, FL. Prior to joining USF in 2009, he was with the transmission asset management department in Midwest ISO, St. Paul, Minnesota from 2002 to 2009. His research interests include power system stability, microgrids, and renewable energy. 